\title{
Correlations of leuko-araiosis with cerebral atrophy and perfusion in elderly normal subjects and demented patients
}

Jun Kawamura, John S Meyer, Makoto Ichijo, Masahiro Kobari, Yasuo Terayama, Susan Weathers

\begin{abstract}
CT images of leuko-araiosis in brain slices were quantified according to volumes of reduced Hounsfield units in frontal periventricular white matter in groups of elderly patients with multi-infarct dementia (MID, $n=23$ ) and dementia of the Alzheimer type (DAT, $n=16)$. Volumes of leuko-araiosis, estimates of atrophic cerebral tissue, and local cerebral perfusion utilising inhalation of xenon gas as the indicator were correlated on the same CT slices. Ratios of frontal leuko-araiosis to total brain tissue volume were similar for patients with MID and DAT (mean 5.7 (SD $2 \cdot 1) \% v 6.5(3 \cdot 2 \%)$ ), and both were significantly greater than ratios in elderly normal volunteers $(3 \cdot 1(1 \cdot 3) \%, 0<0 \cdot 001)$. Cerebral atrophy (measured as the ratio of volumes of cerebrospinal fluid to total brain area) for DAT patients was $17 \cdot 0$ $(6 \cdot 7) \%$, which was greater than for MID patients $(12.5(5.4) \% ; p<0.05)$ and both types of patients showed more cerebral atrophy than did age matched, elderly normal subjects. Cerebral perfusion was decreased in all regions measured in patients with MID and DAT compared with elderly normal subjects. Multi variate regression analyses correlated frontal leuko-araiosis with reductions of local cerebral blood flow in subcortical grey matter $(p<0.025)$ in patients with vascular dementia but not in those with DAT. These quantitative measures implicate decreased perfusion due to atherosclerosis in territories supplied by the deep penetrating cerebral arteries in the pathogenesis of leuko-araiosis in patients with vascular dementia, but suggest a different pathogenesis for leuko-araiosis in Alzheimer's disease.
\end{abstract}

( Neurol Neurosurg Psychiatry 1993;56:182-187)

Interest has been focused on periventricular lucencies of white matter of unknown origin detected by CT scanning of the brain since Hachinski termed them "leuko-araiosis" in 1987 to emphasise their uncertain aetiology, but these white matter lesions were described as early as $1980 .^{23}$ Leuko-araiosis has been associated with ageing, hypertension, risk factors for stroke, a history of symptomatic cerebral ischaemia, minor neurological signs, and impaired cognitive performance. ${ }^{4-8}$ Since the advent of magnetic resonance imaging, white matter lesions have been detected even more frequently among neurologically normal and asymptomatic elderly subjects, confirming that white matter lesions are often clinically silent. ${ }^{910}$

The pathogenesis of leuko-araiosis and its relation to cerebral ageing and cognitive impairment remains unclear. Clinical and neuropathological observations have suggested that ischaemia of white matter may have an important role in the pathogenesis of leukoaraiosis. Without methods to quantitate leukoaraiosis, however, its severity could not be correlated with brain atrophy and local cerebral blood flow, although some indirect comparisons have been made. ${ }^{1112}$

The present study was designed to elucidate the pathogenesis of leuko-araiosis by quantifying it and comparing it with brain atrophy and local cerebral blood flow (LCBF) among elderly demented patients and age-matched normal volunteers. Stable xenon contrast computed tomography of cerebral blood flow was used to measure local cerebral perfusion, and results were correlated with quantitative measurements of frontal leuko-araiosis and the degree of cerebral atrophy determined on the same CT slices of the brain.

\section{Subjects and methods}

SUBJECTS

As summarised in table 1, 23 elderly patients with multi- infarct (MID) and 17 patients with dementia of Alzheimer type (DAT) were admitted to the study, and results were compared with 16 age-matched volunteers who were neurologically and cognitively normal. All subjects signed informed consent according to protocols approved annually by the Institutional Review Board of the Department of Veterans Affairs Medical Centre, Houston, Texas.

Participating subjects underwent similar assessments, which included medical and neurological examinations, cognitive capacity screening examinations (CCSE), ${ }^{13}{ }^{14}$ Hachinski ischaemic index scoring, ${ }^{15}$ and clinical and laboratory testing to determine if any risk factors for stroke were present. Diagnosis of dementia was made according to recommendations of the Diagnostic and Statistical Manual of Mental Disorders (DSM-III-R). ${ }^{16}$ Demented patients had to score consistently less than 24 on serial CCSE examinations. CCSE scores below 25 correlate well with impairments of activities of daily living and other neuropsychological and neurobehavioural test instruments, 
Table 1 Age, gender, and cognitive capacity screening examination (CCSE) scores in demented patients and age-matched normal volunteers

\begin{tabular}{llll}
\hline & $\begin{array}{l}\text { Normal volunteers } \\
(n=16)\end{array}$ & $\begin{array}{l}\text { Patients with MID } \\
(n=23)\end{array}$ & $\begin{array}{l}\text { Patients with DAT } \\
(n=17)\end{array}$ \\
\hline Mean (SD) age & $67 \cdot 2(10 \cdot 5)$ & $64 \cdot 4(10 \cdot 2)$ & $71 \cdot 5(5 \cdot 1)$ \\
Age range & $54-86$ & $51-80$ & $62-79$ \\
Gender (M/F) & $5 / 11$ & $14 / 9$ & $6 / 11$ \\
$\begin{array}{l}\text { Mean (SD) CCSE } \\
\text { scores }\end{array}$ & $29 \cdot 0(1 \cdot 7)$ & $20 \cdot 8(6 \cdot 7)$ & $12 \cdot 4(7 \cdot 1)$ \\
\hline
\end{tabular}

MID = Multi-infarct dementia; DAT = Dementia of Alzheimer type.

including the Wechsler adult intelligence scale $^{14}$; they provide reliable quantitative indices for dementia. Diagnosis of MID required Hachinski ischaemic scores above 7 . Confirmation of cerebral infarctions by CT and MRI was obtained after the clinical diagnosis had been established in patients with MID.

Diagnosis of probable DAT met the criteria provided by the work group of the National Institute of Neurological and Communicative Disorders and Stroke and the Alzheimer's Disease and Related Disorders Association (NINCDS-ADRDA. ${ }^{17}$ To be classified as DAT, patients were required to have Hachinski ischaemic scores below 4 as well as an absence of cerebral infarctions confirmed by CT scanning.

Normal volunteers were recruited through articles in local magazines describing ongoing prospective studies of ageing and from lectures to community groups concerned with the problems of ageing. Criteria for normal volunteers included normal neurological and CCSE examinations; absence of history of stroke or neurological or psychiatric disorders; and exclusion by $\mathrm{CT}$ and MRI of intracranial abnormalities other than age-related cerebral atrophy. To obtain suitable age matching among subjects, normal volunteers below 55 years of age were excluded.

\section{MEASUREMENTS OF CEREBRAL BLOOD FLOW}

Theoretical background

Xenon gas is a lipid soluble $x$ ray contrast indicator which absorbs transmitted $x$ rays, so that its concentration in different tissues may be detected and quantified by CT scanning. After xenon has been inhaled, time dependent changes of its concentration in different brain tissues cause directly proportional changes in CT or Hounsfield numbers. Local changes in tissue concentrations of xenon gas over time are used to measure local cerebral blood flow according to the basic monoexponential equation described by Kety. ${ }^{18}$ According to Kety's model, time dependent increases of diffusible indicator of the brain may be represented by the formula:

$$
\mathrm{Ci}(\mathrm{T})=\lambda i k i \int_{0}^{\mathrm{T}} \mathrm{Ca}(\mathrm{t}) \mathrm{e}^{-\mathrm{ki}(\mathrm{T}-\mathrm{t})} \mathrm{dt}
$$

where $T$ is the time given after starting inhalation of xenon; $\mathrm{Ci}(\mathrm{T})$ the regional enhancements for different regions of interest in brain tissue measured as changes in CT numbers determined at time $T$; $\lambda i$ the brainblood partition coefficient for xenon; and ki the flow rate constant. Arterial input function $\mathrm{Ca}(\mathrm{t})$ is approximated by the equation

$$
\mathrm{Ca}(\mathrm{t})=\operatorname{Camax}\left(1-\mathrm{e}^{-\mathrm{rt}}\right)
$$

where $\mathrm{Ca}(\mathrm{t})$ is the arterial xenon concentration at time $\mathrm{t} ; \mathrm{Ca}(\max )$ the arterial xenon concentration at infinity; and $r$ the rate constant for arterial saturation with xenon. LCBF is then calculated by

$$
\mathrm{LCBF}=i \mathrm{iki}
$$

\section{Procedure}

Local cerebral blood flow was measured in all subjects by serial CT scanning during inhalation of $27 \%$ stable xenon as the contrast agent for eight minutes (Xe CT-CBF method). Details of the method have been reported previously. ${ }^{19}$ Patients and volunteers fasted for six hours before CBF measurements. Subjects reclined on the CT table while inhaling $100 \%$ oxygen for two to four minutes. In all subjects, CT levels for CBF measurements were selected to include frontal, temporal, and occipital cortex; caudate nucleus; putamen; and thalamus. In 8 of 16 elderly normal volunteers, 5 of 23 patients with $\mathrm{MID}$, and 7 of 17 patients of DAT, LCBF values at a second level $10 \mathrm{~mm}$ above the basal ganglia were also measured concurrently. The second level included parietal cortex and parietal white matter. After two baseline non-contrasted CT scans for each CT level were obtained, seven CT scans for each CT level were recorded at one minute intervals between the second and eighth minutes of xenon gas inhalation utilising one of two high resolution rapid CT scanners (Somatom DR version $\mathrm{H}$, Siemens Medical Systems, Iselin New Jersey, USA or Picker Synerview SX 1200, Picker International, Ohio, USA) and xenon gas delivery system (Enhancer 3000, Diversified Diagnostic Products, Houston, Texas). The CT scanning parameters were 96 $\mathrm{kVp}, 540 \mathrm{mAs}, 8 \mathrm{~mm}$ slice thickness with five second scanning times for Somatom DR-H and $130 \mathrm{kVp}, 140 \mathrm{mAs}, 10 \mathrm{~mm}$, two seconds for Picker Synerview for each scan in the serial CT measurements. End tidal partial pressures for xenon gas (PEXe) and carbon dioxide $\left(\mathrm{PECO}_{2}\right)$ were obtained from their respective percentage volume values and corrected for barometric pressure measured at the time of the LCBF measurements.

LCBF values were generated as colour coded images for each brain slice by using a desk top computer (Elegance 425i, Northgate Computer Systems, Minneapolis, MN, USA) programmed to utilise two control scans as baseline and seven postenhancement scans to determine local Xe tissue saturation curves by Kety's formula. The original CT images (512 $\times 512$ pixels) were compressed to $128 \times 128$ voxels before LCBF values were calculated. Effective voxel areas covered for each brain slice are $1.82 \times 1.82 \mathrm{~mm}$ for Siemens Somatom DR-H and $1.88 \times 1.88 \mathrm{~mm}$ for Picker Synerview, hence the volumes of each voxel analysed are $26.5 \mathrm{~mm}^{3}$ and $35.3 \mathrm{~mm}^{3}$ according to the thickness of the CT slices used. By identifying specific anatomical locations on the plain CT images and by using the cursor, LCBF values representing 11 regions for each hemisphere (a total of 22 regions including frontal, temporal, parietal, and occipital cortex; caudate nucleus; putamen, and thalamus; 
frontal, parietal, and occipital white matter; and internal capsular white matter) were computed. Values for LCBF in cortical grey matter (average of frontal, temporal, and occipital cortex), subcortical grey matter (average of caudate, putamen, and thalamus), and white matter (average of frontal, occipital, and capsular white matter) at the level of the basal ganglia were also calculated. EEG and EKG were monitored throughout the CBF measurements.

QUANTIFICATION OF LEUKO-ARAIOSIS AND CEREBRAL ATROPHY

Hounsfield unit numbers for each $C T$ voxel were obtained from the baseline pre-enhanced CT images at the level of the basal ganglia. With these values, volumes for leuko-araiosis in white matter adjacent to the anterior horns of both lateral ventricles and anterior to the heads of both caudate nuclei were quantified by computerised densitometry for those volumes of cerebral parenchyma showing Hounsfield numbers that fell within a window set between the two thresholds for leuko-araiosis. To determine the upper and lower threshold values for leuko-araiosis, two of us independently determined the threshold values for Hounsfield units in all subjects and superimposed the densitometric results on the original non-contrasted brain images. All independent determinations were in good agreement if the lower threshold for leukoaraiosis was set at 25 Hounsfield units and the upper was set at 34. Areas of leuko-araiosis were expressed as percentage ratios to parenchymal areas at the CT level of basal ganglia. With densitometric methods similar to those described previously, ${ }^{20}$ cerebral atrophy was measured as total volumes within the subarachnoid spaces, ventricles, and infarcted brain on the same CT image by utilising values for Hounsfield units below 25 (that is, for cerebrospinal fluid). Results were then expressed as percentage ratios for cerebrospinal fluid volume to intracranial volume (defined as the cerebral atrophic index).

Data are presented as means (SD). Statistical analyses were performed by Student's two tailed $t$ test. To estimate the relative contribu-

Figure 1 Plots and mean (SD) values for frontal leuko-araiosis in patients with multi-infarct dementia (MID, closed circles) and dementia of Alzheimer type (DAT, open triangles) compared with age matched normal volunteers (open circles). Leuko-araiosis in MID and DAT patients is significantly more severe than among normal subjects.

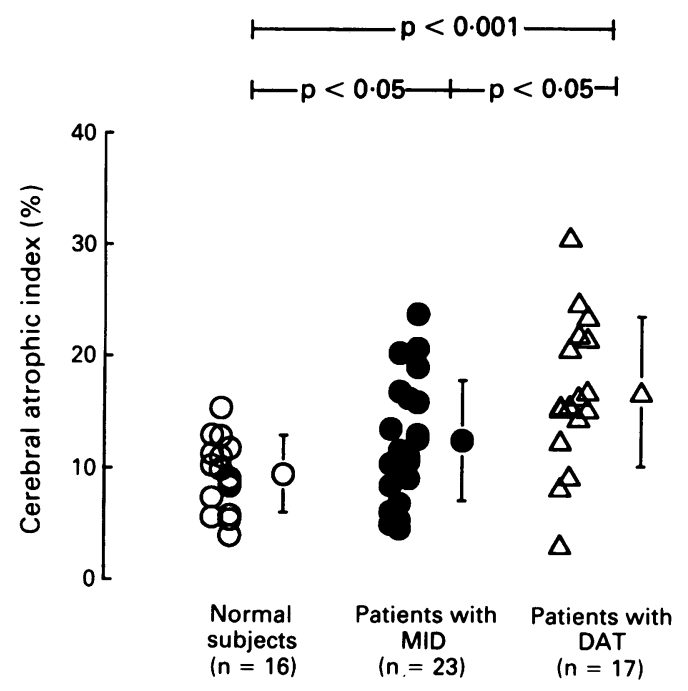

Figure 2 Plots and mean (SD) values of cerebral atrophic indices in demented patients and normal volunteers. Both multi-infarct dementia (MID) and dementia of Alzheimer type (DAT) patients showed greater cerebral atrophy or infarcted brain areas, or both, than normal subjects. Cerebral atrophy in patients with $D A T$ was significantly more severe than in those with MID.

tions of reductions of LCBF to the severity of leuko-araiosis, linear multiple regression analyses were performed. The ratios of leukoaraiosis were regarded as the dependent variable and LCBF values for cortical and subcortical grey matter as well as white matter served as explanatory variables. The algorithm used for computation included stepwise entry and removal of the independent variables $(F$ entry and $F$ removal, $2 \cdot 0$ ).

\section{Results}

Figure 1 shows measured ratios for frontal leuko-araiosis among patients with dementia compared with age matched normal volunteers. The severity of leuko-araiosis was significantly greater in demented patients than in normal volunteers. No differences were apparent in the severity of leuko-araiosis between patients with MID and those with DAT.

Figure 2 summarises cerebral atrophic indices among demented patients compared with age-matched normal volunteers. Both DAT and MID patients exhibited more cerebral atrophy than normal volunteers. Furthermore, cerebral atrophy among patients with DAT was more severe than among those with MID.

Figure 3 shows a non-contrasted CT image of the brain beside the same image with superimposed LCBF values, recorded from a 68 year old man with mild MID. LCBF values were severely reduced in a patchy manner related to numerous lacunar infarcts. Perfusion of the thalamus was decreased bilaterally.

Figure 4 compares LCBF values from nine representative cerebral regions among patients with MID, DAT, and elderly normal volunteers. In patients with MID all LCBF values, except those for parietal white matter, were significantly lower than those in elderly normal volunteers. Likewise, LCBF values were lower for most regions in patients with DAT, 


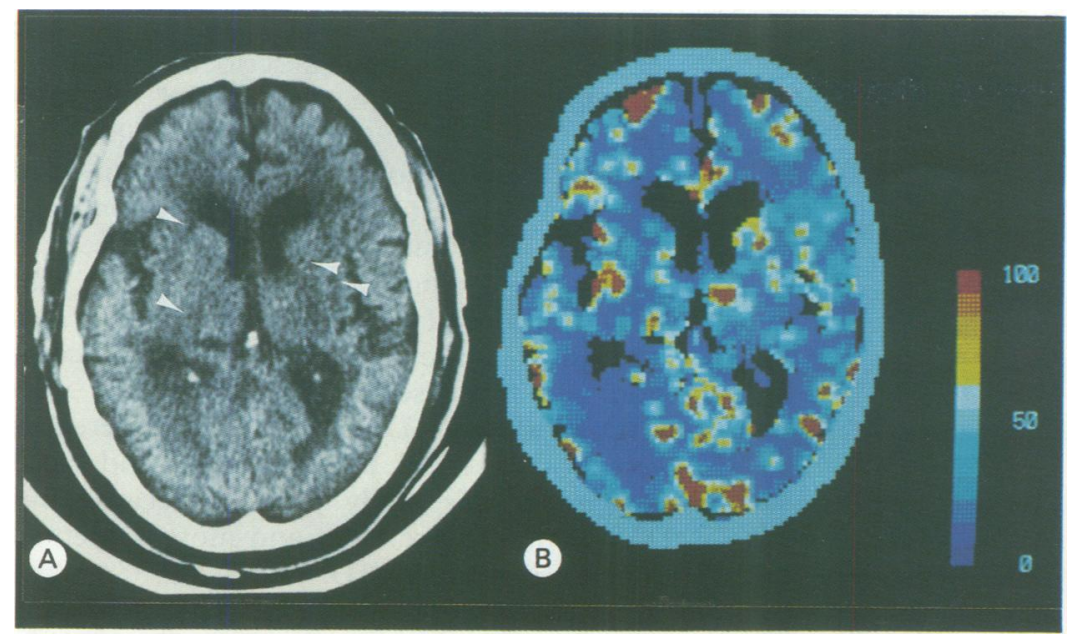

Figure 3 Non-contrast $C T$ image of the brain $(A)$ with superimposed local cerebral blood flow map (B) in a 68 year old man with multi-infarct dementia, hypertension, hyperlipidaemia and CCSE score of 15. Multiple lacunae present in basal ganglia (white arrows) with marked cortical atrophy and prominent leuko-araiosis of deep frontal white matter. Ratios for frontal leuko-araiosis and cerebral atrophy were $7 \cdot 2$ and $23 \cdot 8$ respectively. Cerebral perfusion was reduced in a patchy manner (mean LCBF for cortical grey matter, $33 \mathrm{ml} / 100 \mathrm{~g}$ brain/min; for subcortical grey matter, 31; and for white matter, 14). tal leuko-araiosis were found only in patients with MID (regression equation: percentage of frontal leuko-araiosis $=6.7+0.88 \times$ cerebral atrophic indices; $r=0.57, \mathrm{p}<0.005)$. Correlations between loss of brain parenchyma and severity of frontal leuko-araiosis in patients with DAT $(r=0.47)$ and in normal volunteers $(r=0 \cdot 34)$ were not significant.

Partial pressures for end tidal carbon dioxide $\left(\mathrm{PECO}_{2}\right)$ did not differ significantly between elderly normal volunteers $(33.6(4.5) \mathrm{mm}$ $\mathrm{Hg})$, patients with MID $(32.0(2 \cdot 4)$, and patients with DAT $(31 \cdot 1(3 \cdot 9))$. Nor were significant differences found between mean arterial blood pressure values measured among the three groups [normal volunteers, 95.0 (7.6) $\mathrm{mm} \mathrm{Hg}$; DAT patients, 95.5 (8.7); MID patients, $(97 \cdot 1(11 \cdot 3))$. Alterations in ECG readings were not observed during inhalation of xenon gas in any of the subjects.

\section{Discussion}

Associations between the presence of leukoaraiosis and dementia have often been reported. ${ }^{45821-31}$ Although the presence of white matter lesions detected by CT or MRI was found to be significantly related to cognitive impairment, these associations were qualitative or semiquantitative. In the present study, volumes of leuko-araiosis were quantitated by objective measurements of the volume of reduced Hounsfield numbers present in frontal periventricular white matter.

Recently several investigators have used magnetic resonance imaging to evaluate degrees of leuko-araiosis. Although MRI is a powerful instrument for determining white matter lesions, asymptomatic and unexpected lesions are noted which are frequently not detected by CT scanning. ${ }^{2930}$ The extraordinary sensitivity of MRI often detects trivial white matter lesions without clinical or neuropsychological correlates. ${ }^{29}{ }^{30}$ These observations agree with results of Herholz et al, who were unable to find any correlations between small white matter lesions detected by MRI and reductions of regional blood flow, although correlations were evident between large white matter lesions and reductions of hemispheric perfusion. ${ }^{12}$ The design of the present study permits optimal correlations between severity of leuko-araiosis and reductions of LCBF values since both are measured on the same CT slice.

Table 2 Multiple regression analyses of LCBF values to severity of frontal leuko-araiosis

\begin{tabular}{|c|c|c|c|c|}
\hline$C B F$ region studied & $\begin{array}{l}\text { Partial regression } \\
\text { coefficients }\end{array}$ & $\begin{array}{l}\text { Standardised partial } \\
\text { regression coefficients }\end{array}$ & $\begin{array}{l}\text { Partial correlation } \\
\text { coefficients }\end{array}$ & $p$ value \\
\hline $\begin{array}{l}\text { Cortical grey matter } \\
\text { Subcortical grey matter } \\
\text { White matter }\end{array}$ & $\begin{array}{l}-0.017 \\
-0.000 \\
-0.094\end{array}$ & $\begin{array}{l}\text { Normal volunteers } \\
-0.068 \\
-0.004 \\
-0.221\end{array}$ & $\begin{array}{l}-0.063 \\
-0.004 \\
-0.209\end{array}$ & $\begin{array}{l}\text { NS } \\
\text { NS } \\
\text { NS }\end{array}$ \\
\hline $\begin{array}{l}\text { Cortical grey matter } \\
\text { Subcortical grey matter } \\
\text { White matter }\end{array}$ & $\begin{array}{l}-0.014 \\
-0.127 \\
-0.164\end{array}$ & $\begin{array}{l}\text { Multi-infarct dementia } \\
-0.040 \\
-0.584 \\
-0.198\end{array}$ & $\begin{array}{l}-0.048 \\
-0.529 \\
-0.194\end{array}$ & $\begin{array}{l}\text { NS } \\
<0.025 \\
\text { NS }\end{array}$ \\
\hline $\begin{array}{l}\text { Cortical grey matter } \\
\text { Subcortical grey matter } \\
\text { White matter }\end{array}$ & $\begin{array}{r}0.256 \\
0.098 \\
-0.362\end{array}$ & $\begin{array}{c}\text { Dementia of Alzheimer type } \\
0.426 \\
0.299 \\
-0.325\end{array}$ & $\begin{array}{r}0.365 \\
0 \cdot 271 \\
-0.262\end{array}$ & $\begin{array}{l}\text { NS } \\
\text { NS } \\
\text { NS }\end{array}$ \\
\hline
\end{tabular}




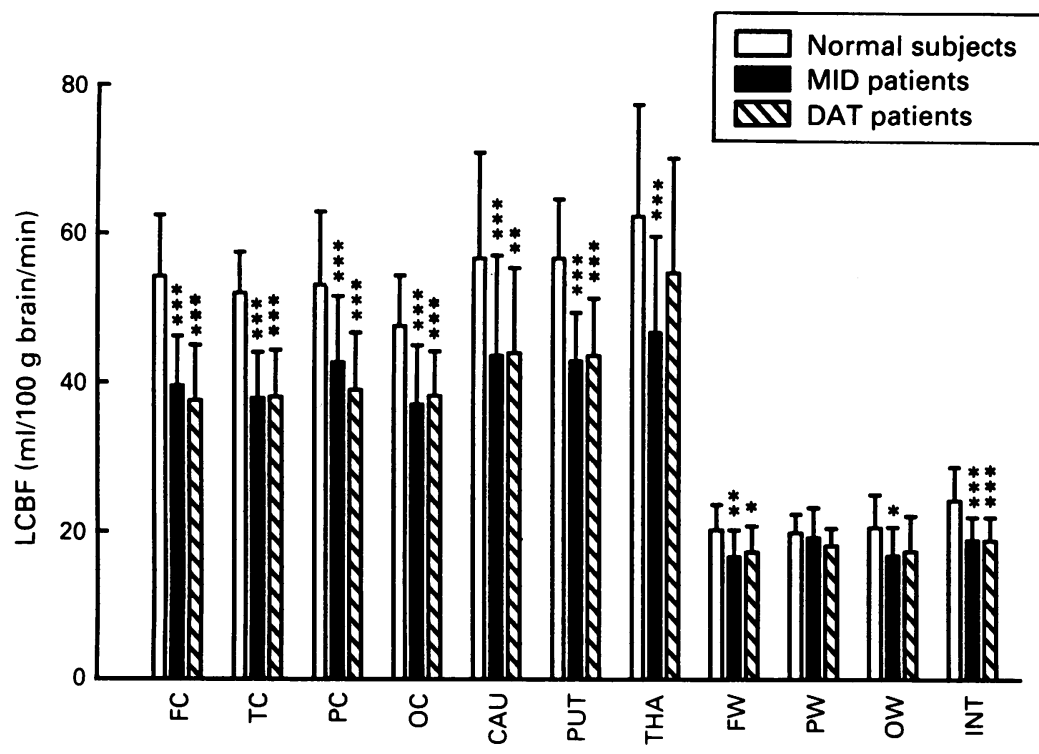

Figure 4 Pooled local cerebral blood flow (LCBF) values (mean (SD) for 11 representative regions in patients with dementia of Alzheimer type (DAT) or multi-infarct dementia (MID) and normal volunteers. Values for $L C B F$ in patients with DAT and $M I D$ were significantly reduced compared with normal volunteers. FC = frontal cortex; $T C=$ temporal cortex; $P C=$ parietal cortex; $O C=$ occipital cortex; $C A U=$ caudate nucleus; $P U T=$ putamen; $T H A=$ thalamus; $F W=$ frontal white matter; $P W=$ parietal white matter; $O W=$ occipital white matter; INT = internal capsule. Significance of differences from elderly normal volunteers: ${ }^{\star} p<0.05,{ }^{\star} p<0.01,{ }^{\star \star \star} p<0.001$.

CT levels selected for measurements included basal ganglia and anterior horns of the lateral ventricles, where leuko-araiosis is most often detected, so that correlations are possible between the severity of frontal leukoaraiosis and perfusion of subcortical structures such as the thalamus and caudate and lentiform nuclei. In addition, in many elderly normal volunteers and MID patients, the LCBF values for parietal cortex and white matter were measured concurrently. Reductions of LCBF values for parietal cortex and white matter were more often present in patients with MID and DAT than in elderly normal subjects, but did not reach statistical significance in parietal white matter, probably because the numbers analysed at this level were too small. The absence of significant reductions in CBF in the thalamus among patients with DAT indicates that in DAT patients the thalamus is relatively well preserved, unlike MID patients. These results are consonant with neuropathological observations as reported by Brun and Englund. ${ }^{32}$

Leuko-araiosis was quantified as voxels of white matter having Hounsfield units falling between 34 and 25 in sections $8-10 \mathrm{~mm}$ thick, which is an optimal method for quantifying leuko-araiosis according to Hachinski's definition of changes in white matter with "decreased density on CT". It is possible, however, that tissues selected by the CT criteria used as showing leuko-araiosis may include some normal white matter due to partial volume or tissue overlap effects and because some variability exists for Hounsfield unit values in normal white matter.

Despite these limitations of the methods described, more leuko-araiosis was found in patients with MID and DAT than in elderly normal volunteers, which adds quantitative support to previously described qualitative relations of leuko-araiosis and dementia. $5782122252729-32$ Concerning possible relations of leuko-araiosis to the pathogenesis of these two different types of dementia, we were unable to determine differences in degrees of leuko-araiosis among patients with DAT and MID. Erkinjuntti et al and Aharon-Peretz et al concluded that leuko-araiosis was more common and more severe among patients with MID than with DAT. ${ }^{225}$ Such differences were not observed between DAT and MID patients in this study possibly because our DAT patients were older and more demented than patients with MID.

In patients with MID, decreases in cerebral perfusion supplying the basal ganglia correlate directly with the severity of leuko-araiosis. Clinical and neuropathological correlations suggest that leuko-araiosis may be caused by cerebral hypoperfusion combined with the well known local anatomical vulnerability to ischaemia of white matter surrounding the frontal horns of the lateral ventricles. ${ }^{711} 123132$ Direct correlations between the severity of leukoaraiosis and hypoperfusion of basal ganglia suggest that ischaemia exists within the territories of the deep cerebral perforating arteries as these vessels supply both periventricular white matter and basal ganglia. Disconnections between cortical grey matter and basal ganglia resulting from leuko-araiosis may exacerbate these local reduced perfusions.

The pathogenesis of white matter lesions causing leuko-araiosis among patients with DAT remains to be determined. As reported by Leys et al, leuko-araiosis in DAT patients may be accounted for, in part, by Wallerian degeneration secondary to neuronal loss. ${ }^{33}$ However, Brun and Englund concluded from detailed neuropathological examinations of patients dying with DAT that some white matter lesions were due to ischaemic change, since arterioles supplying abnormal white matter showed "hyaline degeneration" with stenosis and pial and meningeal vessels showed congophilic changes, although immunochemical stains for amyloid were not carried out. ${ }^{32}$ These authors also noted that leuko-araiosis in DAT patients occurred independently of the presence of neurofibrillary changes, neuritic plaques, and atrophy of grey matter. Taken together, the results support Hachinski's suggestion that amyloid angiopathy in DAT patients may cause ischaemia of white matter and contribute to leuko-araiosis. ${ }^{34}$ This view has been confirmed by immunochemical staining for amyloid in postmortem studies of patients with DAT and among patients with hereditary cerebral infarction and haemorrhage due to amyloidosis of the Dutch type. ${ }^{35}$ Furthermore, amyloid angiopathy affects the pial vessels more than the deep penetrating arteries.

We concluded that leuko-araiosis of frontal white matter quantified by CT imaging is sometimes present in normal elderly subjects, but is greater in degree among elderly patients with vascular dementia and Alzheimer's 
dementia. In patients with vascular dementia, volumes of leuko-araiosis correlate directly with decreased perfusion of basal ganglia supplied by deep cerebral perforating arteries. Although these observations are compatible with an ischaemic hypothesis for the pathogenesis of leuko-araiosis in MID, the pathogenesis of leuko-araiosis in DAT remains to be established. Amyloid angiopathy may be the key contributor.

Barbara W Clark and Dianne Bailey processed the manuscript. Ada Hinds and James Simon provided technical assistance with CT scanning. This work was supported by a grant from the Department of Veterans Affairs, Central Office, Washington,
DC, USA.

1 Hachinski VC, Potter P, Merskey H. Leuko araiosis. Arch Neurol 1987;44:21-3.

2 Valentine AR, Moseley IF, Kendall BE. White matter abnormality in cerebral atrophy: clinicoradiological correlations. f Neurol Neurosurg Psychiatry 1980;43:139-42.

3 Zeumer H, Schonsky B, Sturm KW. Predominant white matter involvement in subcortical arteriosclerotic encephalopathy (Binswanger disease). $\mathcal{F}$ Comput Assist Tomogr 1980;4:14-9.

4 Steingart A, Hachinski VC, Lau C, Fox AJ, Diaz F, Cape R, et al. Cognitive and neurologic findings in subjects with diffuse white matter lucencies on computed tomographic scan (leuko araiosis). Arch Neurol 1987;44:32-5.

5 Steingart A, Hachinski VC, Lau C, Fox AJ, Fox H, Lee D, et al. Cognitive and neurologic findings in demented patients with diffuse white matter lucencies on computed patients with diffuse white matter lucencies on computed
tomographic scan (leuko araiosis). Arch Neurol 1987; tomographic

6 Inzitari D, Diaz F, Fox A, Hachinski VC, Steingart A, Lau $\mathrm{C}$, et al. Vascular risk factors and leuko araiosis. Arch Neurol 1987;44:42-7.

7 Gupta SR, Haheedy MH, Young JC, Ghobrial M, Rubino FA, Hindo $W$. Periventricular white matter changes and dementia. Clinical, neuropsychological radiological, and pathological correlation. Arch Neurol 1988;45:637-41.

8 Junque C, Pujol J, Vendrell P, Bruna O, Jodar M, Ribas JC, et al. Leuko araiosis on magnetic resonance imaging and speed of mental processing. Arch Neurol 1990;47:151-6.

9 Awad IA, Spetzler RF, Hodak JA, Awad CA, Carey R. Incidental subcortical lesions identified on magnetic Incidental subcortical
resonance imaging in the elderly. I. Correlation with age

10 George AE, de Leon MJ, Kalnin A, Rosner L, Goodgold A, Chase N. Leukoencephalopathy in normal and pathologic aging. 2. MRI of brain lucencies. AfNR 1986;7:567-70.

11 Fazekas F, Niederkorn $K$, Schmidt R, Offenbacher $H$, Horner S, Bertha G, et al. White matter signal abnormalities in normal individuals: correlation with carotid ultrasonography, cerebral blood flow measurements, and cerebrovascular risk factors. Stroke 1988;19:1285-8.

12 Kerholz K, Heindel W, Rackl A, Neubauer I, Steinbrich W, Pietrzyk U, et al. Regional cerebral blood flow in patients with leuko araiosis and atherosclerotic carotid artery disease. Arch Neurol 1990;47:392-6.

13 Jacobs JW, Bernhard MR, Delgado A, Strain JJ. Screening for organic mental syndromes in the medically ill. Ann Intern Med 1977;86:40-6.

14 Hershey LA, Jaffe DF, Greenough PG, Yang S-L. Validation of cognitive and functional assessment instruments in vascular dementia. Int $f$ Psychiatry Med 1987;17: 183-92
15 Hachinski VC, Iliff LD, Zilhka E, DuBoulay GH, McAllister VL, Marshall J, et al. Cerebral blood flow in dementia. Arch Neurol 1975;32:632-7.

16 American Psychiatric Association. Diagnostic and Statistical Manual of Mental Disorders. 3rd ed. Washington, DC: American Psychiatric Association, 1987:103-7.

17 McKhann G, Drachman D, Folstein M, Katzman R, Price D, Stadlan EM. Clinical diagnosis of Alzheimer's disease: report of the NINCDS-ADRDA Work Group under the report of the NINCDS-A of Department of Health and Human Services Task Force on Alzheimer's disease. Neurology 1984; 34:939-44.

18 Kety SS. The theory and applications of the exchange of inert gas at the lungs and tissues. Pharmacol Rev 1955; inert gas

19 Meyer JS, Shinohara T, Imai A, Kobari M, Sakai F, Hata T, et al. Imaging local cerebral blood flow by Xe-enhanced computed tomography: technical optimisation procedures. Neuroradiology 1988;30:283-92.

20 Kawamura J, Meyer JS, Terayama Y. Cerebral hypoperfusion correlates with mild and parenchymal loss with severe multi-infarct dementia. I Neurol Sciences 1991;102:32-8.

21 Rezek DL, Morris JC, Fulling KH, Gado MH. Periventricular white matter lucencies in senile dementia of the Alzheimer type and in normal aging. Neurology 1987; 37:1365-8.

22 Erkinjuntti T, Ketonen L, Sulkava R, Sipponen J, Vuorialho $M$, Iivanainen $M$. Do white matter changes on MRI and
CT differentiate vascular dementia from Alzheimer's CT differentiate vascular dementia from Alzheimer's
disease? $₹$ Neurol Neurosurg Psychiatry 1987;50:37-42.

23 Hershey L, Modic MT, Greenough PG, Jaffe DF. Magnetic resonance imaging in vascular dementia. Neurology 1987;37:29-36.

24 Fazekas F, Chawluk JB, Alavi A, Hurtig HI, Zimmerman RA. MR signal abnormalities at $1.5 \mathrm{~T}$ in Alzheimer's dementia and normal aging. AfNR 1987;8:421-6.

25 Aharon-Peretz J, Cummings JL, Hill MA. Vascular dementia and dementia of the Alzheimer type. Cognition, ventricular size, and leuko araiosis. Arch Neurol 1988. 45:719-21.

26 Rao SM, Mittenberg W, Bernardin L, Haughton V, Leo GJ. Neuropsychological test findings in subjects with leuko araiosis. Arch Neurol 1989;46:40-4.

27 Janota I, Mirsen TR, Hachinski VC, Lee DH, Merskey H. Neuropathologic correlates of leuko araiosis. Arch Neurol Neuropathologic
1989;46:1 124-8.

28 Kertesz A, Polk M, Carr T. Cognition and white matter changes on magnetic resonance imaging in dementia. Arch Neurol 1990;47:387-91.

29 Reed KM, Rogers RL, Meyer JS. Cerebral magnetic resonance imaging compared in Alzheimer's and multiinfarct dementia. $\mathcal{F}$ Neuropsychiatry Clin Neurosci 1991; 3:51-7.

30 Kobari M, Meyer JS, Ichijo M, Oravez WT. Leuko araiosis. Correlation of MR and CT findings with blood flow, atrophy, and cognition, $A \mathcal{F N R}$ 1990;11:273-81.

31 Kobari M, Meyer JS, Ichijo M. Leuko araiosis, cerebral atrophy, and cerebral perfusion in normal aging. Arch Neurol 1990;47:161-5.

32 Brun A, Englund E. A white matter disorder in dementia of the Alzheimer type: a pathoanatomical study. Ann Neurol 1986;19:253-62.

33 Leys, Pruvo JP, Parent M, Vermersch P, Soetaert G, Steinling $\mathbf{M}$, et al. Could Wallerian degeneration contribute to "leuko araiosis" in subjects free of any vascula disorder? I Neurol Neurosurg Psychiatry 1991;54:46-50.

34 Hachinski VC. The assessment of multi-infarct dementia. Neurol India 1989;37 (suppl):3.

35 Vintners HV, Secor DL, Partridge WM, Gray F. Immunohistochemical study of cerebral amyloid angiopathy, III. Widespread Alzheimer $A_{4}$ peptide in cerebral microvessel Widespread Alzheimer $\mathrm{A}_{4}$ peptide in cerebral microvesse walls colocalises with gamma trace in patients

36 Haan J, Lauser JBK, Zijderveld I, van der Does FGF, Roos AC. Dementia in hereditary cerebral haemorrhage with AC. Dementia in hereditary cerebral haemorrhage with
amyloidosis Dutch type. Arch Neurol 1990;47:965-7. 